\title{
SCIDiC
}

\author{
International Journal of Dentistry and Oral Science (IJDOS) \\ ISSN: 2377-8075
}

\section{Frequency Of Dental Erosion Among Undergraduate Dental Students Of Pakistan}

Research Article

\begin{abstract}
Dr. Hina Zafar Raja ${ }^{1 *}$, Dr. Muhammad Nasir Saleem² , Dr. Ummara Manzoor ${ }^{3}$, Dr. Maryam Mumtaz ${ }^{4}$, Dr. Sarosh Ehsan ${ }^{5}$, Dr. Mariya ${ }^{6}$
\end{abstract}
${ }^{1}$ Professor of Prosthodontics, Institute of Dentistry CMH Lahore Medical College, Abdul Rehman Road, Lahore Cantt, Lahore, Pakistan.

${ }^{2}$ Professor of Prosthodontics, Institute of Dentistry CMH Lahore Medical College, Abdul Rehman Road, Lahore Cantt, Lahore, Pakistan.

${ }^{3}$ FCPS-II Resident, Department of Prosthodontics, Institute of Dentistry,CMH Lahore Medical College, Abdul Rehman Road, Lahore Cantt, Lahore, Pakistan.

${ }^{4}$ FCPS-II Resident, Department of Prosthodontics, Institute of Dentistry,CMH Lahore Medical College, Abdul Rehman Road, Lahore Cantt, Lahore, Pakistan.

${ }^{5}$ Associate Professor, Department of Operative dentistry, College of dentistry,FMH Lahore Medical College, Lahore, Pakistan.

${ }^{6}$ Assistant Professor, Department of Prosthodontics, Sardar Begum Dental College, Peshawar, Pakistan.

\section{Abstract}

Background: Dental erosion is a form of tooth wear which occurs as a result of dissolution of dental hard tissues caused by acids of non-bacterial origin. Erosion can occur due to intrinsic acids (within the body) or extrinsic acids (dietary intake). Erosive lesion due dietary or gastric acids forms smooth lesions which typically appear as cupped occlusal/ incisal and concave buccal/facial surfaces

Objective: The objective of this study was to evaluate the prevalence of dental erosion among undergraduate dental students in various dental colleges of Pakistan.

Material and Method: This study was conducted at Institute of Dentistry, Combined Military Hospital Lahore Medical College, Fatima Memorial Hospital College of Dentistry, Lahore and Sardar Begum Dental College, Peshawar. Sample size calculated was 330 and data was collected over a period of two years. Signs for erosive lesion were observed during clinical examination. Lesions graded according to Basic erosive wear examination (B.E.W.E.) index and reported.

Results: A sample of 330 dental students is taken with the mean age $21.62 \pm 1.17$ years. There were 107 (32.4\%) male and 223 $(67.6 \%)$ female students in the sample. Prevalence of the erosion in the dental students was $14.8 \%(49 / 330)$.

Conclusion: $107(32.4 \%)$ male and $223(67.6 \%)$ female undergraduate dental students were examined for dental erosion .The frequency of dental erosion among dental students was reported to be $14.8 \%$.

Keywords: Tooth Erosion; Students; Dental; Tooth Attrition; Tooth Wea.

\section{Introduction}

Tooth wear results in the loss of dental hard tissues from the tooth surfaces. Factors other than carious lesion,dental trauma, and developmental disorders can lead to this condition [1, 2]. It is an irreversible, non-cariogenic origin process resulting in destruction and functional loss of dental hard tissue. It can manifest as abrasion, attrition, abfraction and erosion or a combination of these processes [3].
Dental erosion is one of the main causes of tooth surface loss of tooth due to exposure of tooth to extrinsic or intrinsic acids which are not produced by bacteria. Severity of erosion can lead to compromised esthetics and decreased vertical dimension of occlusion [4]. The intrinsic acids are mostly originated as a result of gastric reflux (GERD),vomiting along with anorexia, bulimia nervosa, and rumination [5]. Extrinsic acids can act through carbonated beverages, citrus fruit, and food pickled with vinegar. Medications like vitamin C, iron preparations, inhalers used by asthmatic patients and aspirincan also contribute to be a source of extrinsic acid leading to dental erosion [6].

\section{*Corresponding Author}

Prof. Dr. Hina Zafar Raia

Department of Prosthodontics, Institute of Dentistry, CMH Lahore Medical College, 198 G, Model Town, Lahore, Pakistan

Tel: 0092-334-4222341

E-mail: hinazafarraja@gmail.com

Received: July 27, 2021

Accepted: November 10, 2021

Published: November 12,202

Citation: Dr. Hina Zafar Raja, Dr. Muhammad Nasir Saleem, Dr. Ummara Manzoor, Dr. Maryam Mumtaz, Dr. Sarosh Ehsan, Dr. Mariya. Frequency Of Dental Erosion Among Undergraduate Dental Students Of Pakistan. Int J Dentistry Oral Sci. 2021;8(11):4983-4986. doi: http://dx.doi.org/10.19070/2377-8075-210001003

Copyright: Dr. Hina Zafar Raja 2021 . This is an open-access article distributed under the terms of the Creative Commons Attribution License, which permits unrestricted use, distribution and reproduction in any medium, provided the original author and source are credited. 
Dental erosion can manifests as sensitivity, pain ,inefficient mastication, accidental biting of soft tissues (cheek biting), fractured teeth, increased chances of tooth decay, loss of vertical dimensions of occlusion [7]. Early detection of dental erosion can help to reduce and manage the lesion more efficiently.

Different indices can be used to measure tooth wear. Eccles [8] classified tooth wear lesions as early, small and advanced, with no strict criteria definitions, thus allowing wide interpretation. Smith and Knight [9] developed a tooth wear indexto measure and monitor multifactorial tooth wear. Xhonga and Valdmanis [10] divided erosion lesions into four levels by measurement with a periodontal probe but itdid not address the problem of inter- or intra-examiner variability [11]. The index used to measure erosion in this study is BEWE (Basic Erosive Wear Examination) index [12]. BEWE index is a simple tool to use in general practice,it records the most severely affected surface in each sextant. The lesion is graded according to four level score and the cumulative score classified and matched to risk levels which guide the management of the condition. The BEWE allows re-analysis and integration of results from existing studies [12].

In Pakistan, a study was conducted in Karachi about prevalence of dental erosion in school children [13]. No significant studies have been conducted in Pakistan to measure the prevalence of dental erosion among undergraduate dental students, therefore, it is the need of the day such study be conducted to evaluate the extent of dental erosion in undergraduate dental students of Pakistan. It will also impart awareness among young dental students to diagnose and prevent erosion, its causative factors and methods of reducing dental erosion. This study evaluates the prevalence of dental erosion among undergraduate dental students in various dental colleges of Pakistan and highlight the possible etiological factors leading to dental erosion.

\section{Methodology}

This study was conducted at three dental institutes of Pakistan including,Institute of Dentistry, Combined Military Hospital Lahore Medical College, Fatima Memorial Hospital College of Dentistry, Lahore and Sardar Begum Dental College, Peshawar over a period of two years, starting from January 2019 till January 2021. Sample size was calculated using WHO software for sample size collection, which was 330. The margin of error was kept $5 \%$ and confidence interval was $95 \%$.Observational study design was used and the subjects were selected on the basis of non-probability convenient sampling technique. Undergraduate dental students between the age of 19 to 25 years of age, with no systemic diseases were included. Dental students with developmental enamel defects, history of orthodontic treatment, having any dental malocclusion,students taking any medications leading to xeros- tomia (e.g. anti-hypertensive, anti- depressants, anti-cholinergics,anti-psychotics, anti-histamines) and history of radiotherapy were not included.

Informed consent was taken verbally before examining the subject. The clinical examination of first year, second year, third year and final year undergraduate dental student was done using sterilized dental mirrors only. The following areas were examined in the mouth:

\section{Palatal surfaces of maxillary anterior teeth}

2. Lingual surface of mandibular anterior teeth in individuals suffering from GERD.

3. Occlusal surfaces of posterior teeth.

The teeth were marked using the Basic Erosive Wear Examination (BEWE) index. The BEWE scoring system records the most severely affected surface in a sextant. The four level score (Table 1) 12 grades the appearance or severity of wear on teeth from no surface loss (0), initial loss of enamel surface texture (1), distinct defect, hard tissue loss (dentine) less than $50 \%$ of the surface area (2) or hard tissue loss more than $50 \%$ of the surface area (3) [12]. Erosion along with superimposed attrition was considered as erosive lesions while attrition was recorded separately.

\section{Results}

A sample of 330 dental students was taken with the mean age $21.62 \pm 1.17$ years. There were 107 (32.4\%) male and $223(67.6 \%)$ female students in the sample (figure 1).

The frequency of dental erosion in the dental students was reported to be $14.8 \%(49 / 330)$. However, attrition was present in $12.4 \%(41 / 330)$ of the whole sample. The frequency and percentage for the presence of erosion and attrition is given in the Table-2.

When the dental students were evaluated for the erosion through BEWE index, $283(85.8 \%)$ had no erosive tooth wear, 39 (11.8\%) had initial loss of surface texture, and $8(2.4 \%)$ had distinct defect that is hard tissue loss with less than $50 \%$ of surface area. It is worthy to note that in the whole sample, no student had hard tissue loss with more than $50 \%$ of surface area. The distribution of males and females falling in each category of BEWE index is displayed in figure 2. Out of 107 males, $93(87 \%)$ had no erosion, $12(11 \%)$ had initial loss, and $2(2 \%)$ had distinct defect. Almost same percentages are observed for the females.

The Chi-square test of association was applied between gender and erosion that came out to be statistically non-significant. For the males, the prevalence of the erosion was observed to be $14 \%$

Table 1. Criteria for grading erosive wear.

\begin{tabular}{|c|c|}
\hline Score & No erosive tooth wear \\
\hline 0 & Initial loss of surface texture \\
\hline 1 & Distinct defect, hard tissue loss $<50 \%$ of the surface area \\
\hline $2 *$ & Hard tissue loss $\geq 50 \%$ of the surface area \\
\hline $3 *$ & $*_{\text {in scores } 2 \text { and } 3 \text { dentine often is involved }}$ \\
\hline
\end{tabular}


Figure 1.

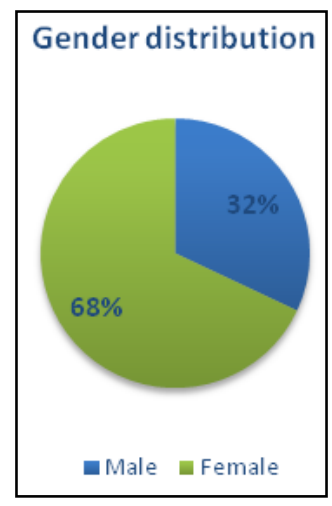

Figure 2.

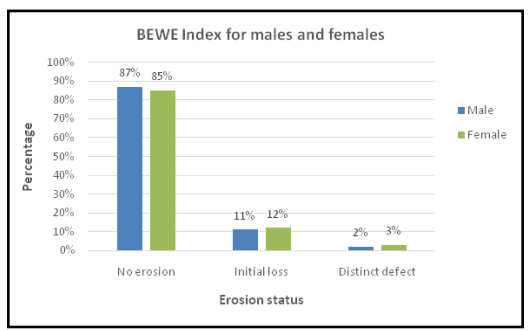

Table 2.

\begin{tabular}{|c|c|c|}
\hline Variables & Absent & Present \\
\hline Erosion & $281(85.2 \%)$ & $49(14.8 \%)$ \\
\hline Attrition & $289(87.6 \%)$ & $41(12.4 \%)$ \\
\hline
\end{tabular}

Table 3.

\begin{tabular}{|c|c|c|c|c|c|}
\hline \multirow{2}{*}{ Gender } & \multicolumn{2}{|c|}{ Erosion } & \multirow{2}{*}{ Total } & $\begin{array}{c}\text { Chi-square } \\
\text { statistic }\end{array}$ & p-value \\
\cline { 2 - 4 } & Absent & Present & & & \\
\hline Male & $92(86 \%)$ & $15(14 \%)$ & 107 & \multirow{2}{*}{0.086} & 0.769 \\
\hline Female & $189(84.8 \%)$ & $34(15.2 \%)$ & 223 & & \\
\hline Total & 281 & 49 & 330 & & \\
\hline
\end{tabular}

$(15 / 107)$ while for females, it was $15.2 \%(34 / 223)$. So, no significant association was found between gender and status of erosion.

\section{Discussion}

The aim of this study wasto evaluate the extent of dental erosion among undergraduate dental students and impart awareness about the diagnosis, prevention and management dental erosion.

Basic Erosive Wear Examination (BEWE) Indexwas used to assess the extent of dental erosion. It was found that $85.8 \%$ students had ' 0 ' BEWE index score. This referred to no active erosive lesion. $11.8 \%$ had initial tooth surface loss, while $2.4 \%$ had distinct defect with hard tissue loss accompanying less than $50 \%$ of surface area. However, it was noted that no subject had hard tissue loss with more than $50 \%$ of surface area, which can bedue to good oral hygiene practices.

In our study the frequency of dental erosion among undergraduate dental students was found to be $14.8 \%$ which is far less than that found in a similar study conducted in China [14] on nonmedical university students, which was found to be $44 \%$. This dif- ference in frequency can be subjected to better understanding of oral health among dental students leading to better dietary habits, restraining of acidic beverages, access to fluorinated water, improved oral hygiene practices including the use a soft-bristled tooth brush with fluoridated toothpaste and avoid using abrasive toothpastes (some whitening toothpastes and charcoal-based toothpastes are more abrasive).

An additional finding of attrition was also found among $12.4 \%$ of dental students. In previous studies [15], it is reported to be $33.3 \%$ among adolescents between the age of 14 to 19 years old. In our study, the students between of 19 to 25 years have reduced stress levels which can contribute low incidence of erosion. Stress can cause vomiting, rumination, anorexia and bulimia nervosa which can lead to dental erosion as well [16]. Decrease in stress level in this age group can bebecause of cultural values and lifestyle, the students mostly are dependent on their families and taken care by elders. They have financial responsibilities to fulfil. Decrease in incidence of dental attrition can also be due to increased awareness of oral health among dental students. Habits like bruxism are addressed earlier and intervened at earlier stages before it can cause any harm. Better oral hygiene practices are encouraged like the use of fluorinated toothpaste and soft tooth brushes. Students 
from Khyber Pakthunwan showed increased incidence of attrition which can be attributed to increase chewing of tobacco.

The study also showed that dental erosion does not show predilection towards gender bias. In the age group between 19 to 25 years of age the difference is not significant statistically, it is observed to be $14 \%$ in males while in females its $15.2 \%$. In a study done in UK, it was found that females practice better oral hygiene and brush more frequently then males [17].

Although the results found in our study are not alarming, the prevalence of dental erosion among undergraduate dental students among demands attention. Dentists should routinely assess the risk of dental erosion among young population for diagnosis and management. Preventive approach should be adopted among dental students to further decrease its incidence and increase awareness among dental students. Awareness among dental students can be increased via seminars, dental conferences, social media campaigns, brochure and poster competition etc.Measures like regular monitoring need to be practiced as part of mini $\neg \mathrm{mal}$ intervention dentistry. Once a preventive approach or any other form of treatment is implemented, follow-up assessments should be made to see if the measures undertaken are successful.18 Monitoring requires a complete reassessment where the history, special tests, color photographs and dental casts are repeated, to note either improvement or otherwise from the original assessment18.

\section{Limitations}

The limitation of this study is that dental erosion was checked among a specific age group 19 to 25 years of age. General population was not considered. The results could vary in different age groups.

\section{Recommendations}

Dental erosion is multifactorial condition. As health providers it is our prime responsibility to identify the possible risk factors and make the community aware of the ways to prevent this condition. Dietary counseling should be done at an early stage in schools and universities, such as, limiting the acidic foods and drinks and their avoidance at night should be stressed. Habits such as frothing or swishing the drink around the mouth or drinking in small sips can be avoided. If a straw is used it can be wide bore and kept at the back of the mouth in order to reduce the contact area between the acid and the teeth. After consumption of an acidic food or drink if tooth brushing is done immediately it would lead to rapid loss of enamel surface.

\section{Conclusion}

The frequency of dental erosion among undergraduate the dental students was found to be $14.8 \%$.However, attrition was present in $12.4 \%(41 / 330)$ of the whole sample. This study suggested percentage of students suffering from dental erosioncan have severe adverse effects in future as the lesion progress.However, no significant association was found between dental erosion and gender of patient. This study will encourage clinicians, students and general dental practitioners to pay more attention to erosive wear and hence will be beneficial for patient care.

\section{References}

[1]. Litonjua LA, Andreana S, Bush PJ, Cohen RE. Tooth wear: attrition, erosion, and abrasion. Quintessence Int. 2003 Jun;34(6):435-46. PubMed PMID: 12859088

[2]. Lussi A. Dental erosion: from diagnosis to therapy: Karger Medical and Scientific Publishers; 2006.

[3]. Imfeld T. Dental erosion. Definition, classification and links. Eur J Oral Sci. 1996 Apr;104(2 ( Pt 2)):151-5. PubMed PMID: 8804882.

[4]. Vailati F, Belser UC. Full-mouth adhesive rehabilitation of a severely eroded dentition: the three-step technique. Part 3. Eur J Esthet Dent. $2008 \mathrm{Au}$ tumn;3(3):236-57. PubMed PMID: 19655541.

[5]. Li BK. Cyclic Vimiting Syndrome: Proceedings of the International Scientific Symposium on Cyclical Vomiting Syndrome Held at St. Bart: LippincottRaven; 1995.

[6]. Milosevic A, Young PJ, Lennon MA. The prevalence of tooth wear in 14-year-old school children in Liverpool. Community Dent Health. 1994 Jun;11(2):83-6. PubMed PMID: 8044716.

[7]. Mehta SB, Banerji S, Millar BJ, Suarez-Feito JM. Current concepts on the management of tooth wear: part 1. Assessment, treatment planning and strategies for the prevention and the passive management of tooth wear. $\mathrm{Br}$ Dent J. 2012 Jan 13;212(1):17-27. PubMed PMID: 22240686.

[8]. Eccles JD. Dental erosion of nonindustrial origin. A clinical survey and classification. J Prosthet Dent. 1979 Dec;42(6):649-53. PubMed PMID: 292776.

[9]. Smith BG, Knight JK. An index for measuring the wear of teeth. Br Dent J. 1984 Jun 23;156(12):435-8. PubMed PMID: 6590081.

[10]. Xhonga FA, Valdmanis S. Geographic comparisons of the incidence of dental erosion: a two centre study. J Oral Rehabil. 1983 May;10(3):269-77. PubMed PMID: 6575167.

[11]. López-Frías FJ, Castellanos-Cosano L, Martín-González J, Llamas-Carreras JM, Segura-Egea JJ. Clinical measurement of tooth wear: Tooth wear indices. J Clin Exp Dent. 2012 Feb 1;4(1):e48-53. PubMed PMID: 24558525.

[12]. Bartlett D, Ganss C, Lussi A. Basic Erosive Wear Examination (BEWE): a new scoring system for scientific and clinical needs. Clin Oral Investig. 2008 Mar;12 Suppl 1(Suppl 1):S65-8. PubMed PMID: 18228057.

[13]. Najmi N, Bugti AA, Nadeem M, Hannan H, Tanwir F, Shafiq F. PREVALENCE AND PREDICTORS OF DENTAL EROSION IN SCHOOL CHILDREN OF KARACHI PAKISTAN. International Journal of Dental Clinics. 2013;5(3).

[14]. Chu CH, Ng A, Chau AM, Lo EC. Dental Erosion and Caries Status of Chinese University Students. Oral Health Prev Dent. 2015;13(3):237-44. PubMed PMID: 25197728.

[15]. Casanova-Rosado JF, Medina-Solís CE, Vallejos-Sánchez AA, CasanovaRosado AJ, Maupomé G, Avila-Burgos L. Dental attrition and associated factors in adolescents 14 to 19 years of age: a pilot study. Int J Prosthodont. 2005 Nov-Dec;18(6):516-9. PubMed PMID: 16335172.

[16]. Scheutzel P. Etiology of dental erosion--intrinsic factors. Eur J Oral Sci. 1996 Apr;104(2 ( Pt 2)):178-90. PubMed PMID: 8804885.

[17]. Al-Dlaigan YH, Shaw L, Smith AJ. Dental erosion in a group of British 14-year-old, school children. Part III: Influence of oral hygiene practises. $\mathrm{Br}$ Dent J. 2002 May 11;192(9):526-30. PubMed PMID: 12047125.

[18]. Kaidonis JA. Oral diagnosis and treatment planning: part 4. Non-carious tooth surface loss and assessment of risk. Br Dent J. 2012 Aug;213(4):15561. PubMed PMID: 22918343. 